\title{
Entre Ciência, Arte e Vida: a didática como ato responsivo
}

Patrícia Corsino' 'Universidade Federal do Rio de Janeiro (UFRJ), Rio de Janeiro/RJ - Brasil

RESUMO - Entre Ciência, Arte e Vida: a didática como ato responsivo. Este ensaio tem como finalidade trazer reflexões para se pensar a didática, entendida como ato responsivo, conceito cunhado por Mikhail Bakhtin que implica no agir como uma resposta responsável dada pelo sujeito que o coloca frente à alteridade. Inicialmente discute conceitos presentes no título. Afirma que é na relação com o outro que o eu se constitui. A didática é uma resposta responsável e não indiferente aos sujeitos a quem o ensino se dirige. Nesta perspectiva, são apresentados princípios para a didática $\mathrm{O}$ referencial teórico que sustenta os argumentos do texto inclui os estudos de Bakhtin, Arendt, Benjamin, Charlot, Vigotski, entre outros.

Palavras-chave: Linguagem. Didática. Ensino/Aprendizagem. Escola. Bakhtin.

ABSTRACT - Between Science, Art, and Life: didactics as a responsive act. This essay aims to bring reflections to think the didactics understood as a responsive act, a concept coined by Mikhail Bakhtin that implies acting as a responsible response provided by the subject that faces him in with the otherness. Initially, it develops the concepts present in the title. It claims that the self is constituted in the relation to the other. The didactics is a responsible answer, not indifferent to the subjects to whom the teaching is aimed at. According to this perspective, principles for the didatics are presented. The theoretical framework supporting the arguments of the essay includes the studies of Bakhtin, Arendt, Benjamin, Charlot, Vigotski, among others. Keywords: Language. Didactics. Teaching/Learning. School. Bakhtin.

Educação \& Realidade, Porto Alegre, v. 40, n. 2, p. 399-419, abr./jun. 2015. 399 http://dx.doi.org/10.1590/2175-623646089 
Entre Ciência, Arte e Vida

O mais alto princípio arquitetônico do mundo real do ato realizado ou ação é a contraposição concreta e arquitetonicamente válida ou operativa entre eu e outro. A vida conhece dois centros de valor que são fundamental e essencialmente diferentes, embora correlacionados um com o outro: eu e o outro, e é em torno destes centros que todos os momentos concretos do ser se distribuem e se arranjam (Bakhtin, 2010, p. 91).

Este texto tem como finalidade trazer reflexões sobre a didática, entendida aqui como ato responsivo. Ato que se instaura cotidianamente na relação entre professores e alunos e que implica em tomadas de posição. Parte do pressuposto de que aquilo que ensinamos e o modo como ensinamos são sempre respostas ao nosso modo de apreender o mundo. O título escolhido se justifica pelo referencial teórico eleito para as reflexões: a filosofia da linguagem de Mikhail Bakhtin.

Ponzio (2010), na introdução do texto de Bakhtin (2010) Para uma filosofia do ato responsável, faz a análise etimológica de alguns termos usados pelo autor. Entre eles destaca a palavra postupok, traduzida como ato. Palavra que contém a raiz stup, passo, podendo ser entendida como dar um passo, tomar iniciativa, fazer um movimento, uma ação arriscada, tomar posição. Ato, assim, se articula a outro conceito de bakhtiniano: exotopia - lugar exterior ocupado pelo sujeito na relação com o outro. Lugar único, singular de onde ele dá o passo, age. Este agir entendido também como resposta a uma escuta. Afirma Ponzio:

[...] postupok é um ato de pensamento, de sentimento, de desejo, de fala, de ação, que é intencional, e que caracteriza a singularidade, a peculiaridade, o monograma de cada um, em sua unicidade, em sua impossibilidade de ser substituído, em seu dever responder, responsavelmente, a partir do lugar que ocupa, sem álibi e sem exceção (Ponzio, 2010, p. 10).

Para Bakhtin (2010), o existir implica no agir, no participar. E agir é tomar uma posição, num dado momento irrepetível. Mas para o autor, ato na sua integridade é responsável. Como seres únicos, cada um ocupa um lugar singular, insubstituível que o obriga a realizar a sua singularidade. E assumir a responsabilidade da unicidade da existência coloca o sujeito frente à alteridade, isto é, nos dois centros de valor diferentes e correlacionados: eu e o outro.

Para o autor, os momentos em que se constituem e se dispõem todos os valores, todos os significados e todas as relações espaço-temporais e de conteúdo-sentido podem ser entendidos como: o eu-para-mim, o outro-para-mim e o eu-para-o-outro. Assim,

[...] tudo o que me diz respeito, a começar por meu nome, e que penetra em minha consciência, vem-me do mundo exterior, da boca dos outros (da mãe etc.), e me é dado com a entonação, com o tom emotivo dos valores deles. Tomo 
consciência de mim, originalmente, através dos outros: deles recebo a palavra, a forma e o tom que servirão a formação original da representação que terei de mim mesmo (Bakhtin, 1992b, p. 278).

É na relação com o outro que o eu se constitui. O outro vê o eu com um fundo que o eu não domina. Ele tem um excedente de visão em relação ao eu, uma experiência do eu que o próprio eu não tem, mas que, por sua vez, tem o mesmo a respeito do outro. Assim, Geraldi alerta para o fato de que "[...] este acontecimento nos mostra a nossa incompletude e constitui o outro como o único lugar possível de uma completude impossível" (Geraldi, 2003, p. 19).

Nossas respostas são formuladas a partir da nossa relação com a alteridade. São contra palavras as palavras do outro. Nas inter-relações entre eu e o outro se confrontam múltiplos discursos e nesta arena nos constituímos e somos constituídos mutuamente, sempre de forma inacabada e provisória. É por isso que Bakhtin afirma que "[...] a única forma adequada de expressão verbal da autêntica vida do homem é o diálogo inconcluso. A vida é dialógica por natureza. Viver significa, então, participar do diálogo; interrogar, ouvir, responder, concordar etc." (Bakhtin, 2003, p. 348). A dialogia é fundante do nosso ser no mundo e o ato responsivo é entendido como a minha responsabilidade em relação ao outro, a minha não indiferença mutuamente constitutiva.

Nesta perspectiva, a didática - como ensinamos o que ensinamos - é um ato responsivo, uma resposta responsável e não indiferente ao outro - sujeitos a quem o ensino se dirige. Mas, como o campo da didática é multidimensional, as respostas também são multidirecionadas. São muitos os outros escutados e respondidos no ato de ensinar e aprender. Ato ético, estético, epistemológico e político no qual a não indiferença é o que move e dá sentido ao passo dado por sujeitos situados, que firmam o seu compromisso com o outro - os vários outros - pelas respostas que dão do seu lugar exotópico, único e sem álibi.

Há mais de trinta anos, Candau convocava os educadores brasileiros a assumirem a perspectiva fundamental ou crítica da didática, tendo em vista "[...] a multidimensionalidade do processo de ensino-aprendizagem que coloca a articulação das dimensões técnica, humana e política no centro configurador de sua temática (Candau, 1991, p. 21)". Assumir esta perspectiva, que rompe com o paradigma de um campo que se assentava como instrumental, aplicativo e técnico implicou e continua implicando em se colocar em constante questão. Significou e tem significado se deslocar em muitas direções, se valer da ambivalência dialética entre teoria e prática que lhe é constitutiva, assumir a imprevisibilidade, a eventualidade do processo de ensinar-aprender, entendendo que as respostas são contingentes e historicamente construídas e que elas aludem aos lugares de onde se dá o passo e ao porvir, já que cada passo desencadeia outros. 
Entre Ciência, Arte e Vida

$\mathrm{O}$ ato responsivo que se dá no encontro e no confronto entre o eu e o outro, frente ao que se ensina e se aprende, longe de se colocar num terreno meramente interpessoal, apresenta uma dimensão social constitutiva, que tem a linguagem como mediação sígnica necessária. Para Bakhtin (2003), a linguagem atravessa a vida e a vida é atravessada pela linguagem. Linguagem e vida são indissociáveis. Linguagem entendida com Geraldi como "[...] trabalho e produto do trabalho e, enquanto tal, cada expressão carrega a história de sua construção e de seus usos” (Geraldi, 2003, p. 20). A didática, que tem como objeto de estudo o ensino enquanto prática social realizada entre sujeitos, se constitui na e com a linguagem em todas as suas formas verbais, não verbais, multimodais: palavras, contra palavras, ditos, presumidos, silêncios, imagens, gestos e expressões. No ato de ensinar e aprender diferentes vozes constituem os sujeitos - vozes de muitos outros que participaram e participam do seu processo de subjetivação - e põem-se à escuta dos sujeitos a quem dirigem as ações. A partir das escutas, organizam respostas possíveis, conforme as condições que cada contexto enunciativo dispõe e possibilita. É possível planejar parte das respostas, pela natureza intencional da didática, entretanto, é no campo das interações, no espaço relacional que se institui em cada ato enunciativo, que são tecidos os sentidos e estabilizados significados partilhados. Assim, os processos de significação que ocorrem nas práticas sociais traduzem a natureza semiótica e dinâmica da sociabilidade e da criatividade humanas (Pino, 2005) evidenciando, que somos simultânea e dialeticamente produto e produtores de cultura. A relação ensino-aprendizagem faz parte deste processo, sendo modificada pela ação e relação de sujeitos - professores e alunos - situados que alteram e são alterados nesse processo.

É ainda Bakhtin (2003), que sustenta a parte inicial do título deste texto Entre a Ciência a arte e a vida. No seu ensaio Arte e responsabilidade afirma que ciência, arte e vida são campos da cultura humana que se articulam, mas tanto podem adquirir unidade no indivíduo que as incorpora, como permanecer cindidos e manter entre si apenas uma relação mecânica e externa. Se a cisão acontece, a arte ou a ciência passam a ser entendidas de forma autônoma, autossuficientes, isoladas da vida. Essa postura mecânica tem consequências éticas que empobrecem culturalmente o homem e, assim, afirma o autor:

O poeta deve compreender que sua poesia tem culpa pela prosa trivial da vida, e é bom que o homem da vida saiba que sua falta de exigência e de seriedade nas questões vitais respondem pela esterilidade da arte. [...] Arte e vida não são a mesma coisa - assim como ciência e vida - mas devem tornar-se algo singular em mim, na unidade da minha responsabilidade (Bakhtin, 2003, p. xxxiv).

A articulação entre ética e criação - na ciência ou na arte - é um desafio à produção de conhecimento e ao próprio agir humano. Esta perspectiva traz questões seminais para se pensar o ato educativo e o 
lugar da didática no processo de construção de nexos. Como articular ciência, arte e vida? A pertinência para a didática é dupla, tanto para pensar o próprio campo, no desafio de articular as suas diferentes dimensões - técnica, humana e política -, quanto para a prática pedagógica, na perspectiva de questionar o ensino: o que pode a didática? Que propostas podem romper com a cisão entre ciência, arte e vida tão comuns no cotidiano escolar? Como articular saberes e conhecimentos de forma a afetar o outro, deslocar o outro, mobilizá-lo na construção de nexos necessários para a apropriação? Qual é o compromisso ético e social da escola com a democratização de conhecimentos científicos e artísticos produzido coletiva e historicamente por diferentes grupos sociais? Qual é o lugar da didática na produção de sentidos?

É ainda Bakhtin (1976), que ao se referir ao discurso da vida e o discurso da arte articula forma e conteúdo, ética e estética. O autor afirma que a seleção do conteúdo e a seleção da forma constituem um único ato estabelecendo a posição básica do criador; e neste ato a mesma avaliação social encontra expressão. $\mathrm{O}$ artista, pela mediação da forma artística, assume uma posição ativa com respeito ao conteúdo. Neste sentido, forma e conteúdo são indissociáveis e marcam a posição do criador. Assim é que a didática se coloca no cerne da prática pedagógica. A síntese entre forma e conteúdo acontece nas propostas e ações didáticas, entre o que e como se ensina e o que e como se aprende. Objetivos, conteúdos, metodologias, recursos, organização do tempo-espaço são escolhas que se articulam axiologicamente e se apresentam de uma determinada forma no ato de ensinar e aprender. É assim que no chão da escola ética e estética se indissociam. É também assim que se efetivam as políticas: nas posições marcadas no agir.

Cabe ressaltar, também, que a ética que tem como base o sentido dialógico da relação $E u$-Tu, postulado por Buber (2009), concebe o dialógico para além do limite do tráfego dos homens entre si; o dialógico como comportamento dos homens um-para-com-o-outro. Uma ética baseada numa não indiferença que tem como centro o perceber, o acolher, o receber, o aceitar o outro no sentido de sua percussão no eu. Buber afirma, "[...] a existência dialógica recebe, mesmo no extremo abandono, uma sensação áspera e revigorante de reciprocidade; a existência monológica não se aventura, nem na mais tenra comunicação, a tatear para fora dos contornos de si mesmo" (Buber, 2009, p. 55). Por esta via, o outro não apenas me constitui, mas me importa. Eu e Tu nos percebemos e nos sentimos mutuamente afetados pelo acolhimento, no encontro com a alteridade.

Feita esta introdução, a seguir serão discutidas questões que compõem escutas e respostas da didática. São apresentados princípios para se pensar a didática como ato responsivo, quais sejam: a educação entre o presente, o passado e o futuro como possibilidade de mudança; linguagem e experiência como luta contra a barbárie, o desenvolvimento e aprendizagem como movimentos do coletivo ao individual, no qual 
Entre Ciência, Arte e Vida

criação, imaginação e conhecimento são produções coletivas de empoderamento individual e social; e a passagem do Eu empírico para o Eu epistêmico como compromisso da didática para ampliação cultural dos estudantes.

\section{Didática: discutindo princípios para o ato responsivo}

Sendo uma área da Pedagogia, a Didática tem no ensino seu objeto de investigação. Considerá-lo uma prática educacional em situações historicamente situadas significa examiná-lo nos contextos sociais nos quais se efetiva [...], estabelecendo os nexos entre eles. As novas possibilidades da Didática estão emergindo das investigações sobre o ensino como prática social viva (Pimenta et al., 2011, p. 17).

Estudos do campo da didática têm firmado sua especificidade como área do ensino comprometida com a aprendizagem. Pimenta et al. (2011) sinalizam que as investigações desta prática social viva, complexa, que se dá de forma contextual e intersubjetiva, têm reconhecido os saberes didáticos construídos pela ação docente, como saberes genuínos e singulares, que compõem uma epistemologia da prática. Estes conhecimentos produzidos pelos professores, suas formas de ensinar forjadas na relação com o conhecimento e com o outro que aprende, são produções que emergem do diálogo entre teoria e prática e ampliam este diálogo: "[...] neste processo, os saberes teóricos propositivos se articulam aos saberes da prática ao mesmo tempo ressignificando-os e sendo, por sua vez, ressignificados" (Pimenta et al., 2011, p. 20).

$\mathrm{O}$ reconhecimento de que a didática produz um conhecimento próprio faz com que deixe de ser concebida como mera aplicação de conhecimento de outras áreas, e ganhe um novo estatuto epistemológico. O lugar de produção dos conhecimentos didáticos é a própria prática pedagógica, onde acontecem as relações entre sujeitos, saberes e conhecimentos. São ainda Pimenta et al. (2011, p. 26) que afirmam que as novas pesquisas em Didática "[...] têm de recolher, articular e interpretar o conhecimento prático dos professores, não para criar uma literatura de exemplo, mas para estabelecer princípios, pressupostos, regras em campo de atuação".

A produção deste conhecimento, por sua vez, se dá no cotidiano de uma turma, com um grupo de crianças, jovens ou adultos, que pertence a uma escola, que se situa num contexto sócio-histórico. Portanto, há condições diversas para produção destes conhecimentos. Não cabe às investigações elaborar literaturas de exemplo, nas refletir sobre os conhecimentos produzidos, relacionar a dimensão micro com a macro e vice-versa, para pensar possíveis respostas para questões da prática. Os processos de ensino-aprendizagem são complexos e fazem parte de práticas sociais que estão diretamente relacionadas à formação dos sujeitos. Às dimensões pessoal, contingente e local, se somam as dimen- 
sões filosóficas, políticas e sociais. O ensino, para ser transformador, exige o exercício constante de reflexão e crítica, diálogo com diferentes áreas, prospecção e engajamento social.

A didática que tem o ensino como seu objeto de estudo, se justifica enquanto um constante recriar de seus métodos, técnicas e teorias frente às necessidades que as situações de ensino geram. Recriação que produz conhecimentos próprios e genuínos, que se articulam às posições tomadas não apenas pelo professor, mas por um coletivo que o constituiu social, cultural, institucional, político. Nesta cadeia de relações mutuamente constitutivas, há um lugar intersubjetivo de produção de sentido e de criação individual e um lugar político do compromisso social do ensino que se pratica. Cada sujeito do ensinar e aprender responde por si e responde também a partir de um lugar coletivo, social, político.

A educação é uma prática social complexa. É contextual, envolve um projeto de sujeito e de sociedade, abarca conhecimentos de diversos campos, processo e ações também diversos. Charlot ao discutir as especificidades da educação aponta um triplo processo: de humanização, de socialização e de entrada numa cultura, e de singularização-subjetivação: "[...] educa-se um ser humano, o membro de uma sociedade e de uma cultura, um sujeito singular” (Charlot, 2006, p. 15). Os três processos se articulam e variam sócio historicamente, conforme se concebe cada um deles e as articulações que se estabelecem entre eles. Mas o autor chama a atenção para o fato de que este processo opera numa tripla articulação entre três ações: o fazer do professor, o fazer do aluno e o fazer da instituição escolar. Conforme o autor,

[...] o trabalho do professor não é ensinar, é fazer 'algo'
para que o aluno aprenda. Com frequência este 'algo' con-
sistirá em ensinar; outras vezes, pode tomar uma outra
forma [...]. A atividade do aluno e do professor operam em
um quadro institucional que define as condições mate-
riais, financeiras, burocráticas etc. (Charlot, 2006, p. 15).

Toda busca do professor de fazer com que o aluno aprenda se dá de forma situada, em condições de produção determinadas, inclui também conhecimentos e afetos já que os agentes envolvidos no ensinar e aprender se afetam mutuamente e se transformam. Há uma articulação entre os três ações do fazer e a didática, enquanto ato responsivo, se encontra nesta articulação de ações contingentes e na busca de transformações.

Tomando a perspectiva de Charlot em relação à especificidade da Educação; o triplo processo de humanização, socialização, singularização associado à articulação entre as três formas de atividade, do aluno, do professor e das políticas; a seguir são tecidos princípios para se pensar a didática. Princípios entendidos como começos, entradas, aberturas. Não há dúvidas de que teriam outros, mas escolhas foram 
feitas para este ensaio, considerando sua abrangência e possibilidade de sustentar o argumento inicial do texto, qual seja, a didática como ato responsivo.

\section{Educação: entre o presente, o passado e o futuro}

Não há resposta sem historicidade. A resposta responsiva ainda que ela seja sempre contingente, realizada no presente, tem dupla direção, volta-se para o passado e para o futuro. Bakhtin (1992a) alerta para o fato de que não há a primeira nem a última palavra, penetra-se num fluxo, onde a compreensão é uma réplica que suscita novas perguntas e outras possibilidades, numa corrente ininterrupta. Esta dialogia que constitui a vida humana é inconclusa e se insere no grande tempo.

A educação como uma prática social e a didática em particular se inserem nesta corrente, são contextuais, respondem a partir de um contexto econômico, político, cultural e suas respostas se lançam para o futuro.

Para Arendt, a responsabilidade pela educação da criança encerra em si uma ambivalência entre a conservação e a renovação do mundo: "A criança requer cuidado e proteção especiais para que nada de destrutivo lhe aconteça de parte do mundo". Porém, também o mundo necessita de proteção, para que não seja “[...] derrubado e destruído pelo assédio do novo que irrompe sobre ele a cada nova geração" (Arendt, 1997, p. 235).

No mesmo ato responsivo de quem educa as crianças reside simultaneamente a preservação do passado, como legado que se disponibiliza aos que chegam, e possibilidade de rompimento, de abertura para o novo e ressignificação da história. Esta perspectiva histórica de transformação do futuro pelo presente que põe o passado em questão aproxima Arendt (1997) e Benjamin (1993). Para o critico da modernidade, a rememoração e reapropriação do passado se fazem necessárias não para repeti-lo de maneira saudosista, mas como possibilidade de romper com o continuum de um tempo linear. Benjamin recusa a ideia de progresso histórico para dar lugar ao tempo como algo que permite instantes de ruptura. A história para Benjamin não está encerrada em um definitivo era uma vez. Há possibilidade dos homens intervirem na história e mudarem o futuro. $\mathrm{O}$ inacabamento do passado se dá justamente pela possibilidade de apreendê-lo a partir do presente, trazer suas ruínas, trabalhar criticamente com os fragmentos e a partir do olhar do presente, quebrar com a continuidade homogênea de um tempo vazio e linear.

Benjamin afirma em uma de suas teses sobre o conceito de história que “[...] nunca houve um monumento da cultura que não fosse também um monumento da barbárie". Assim, a tradição é também testemunha da história dos vencedores e "[...] seu esvaziamento não é necessaria- 
mente um mal, pois enquanto arquivo da injustiça, ela contribui, de certo modo, para perpetuá-la" (Rouanet, 1981, p. 52). Há uma ambivalência na tradição presente na tensão entre a conservação e a ruptura. Se, como anuncia Benjamin, o instante revela possibilidades insuspeitadas do presente, a educação seria, então, uma possibilidade do salto do tigre ao passado para escovar a história a contrapelo; com a escuta da história dos vencidos e a recusa do tempo linear, livrando o passado de seu eterno retorno como dominação.

O ato responsivo da educação estaria no compromisso com a ação que a natalidade enseja: "a permanente e igualitária capacidade de começar algo novo” (Arendt, 1997, p. 349). Um começar algo novo comprometido ética e politicamente com a ressignificação da história, com a superação do instituído que homogeneíza, silencia e oprime, com a abertura de novas possibilidades fora do que está posto.

Neste primeiro princípio reside a condição do fazer cotidiano: a certeza de que a mudança é possível. Aqui o ato responsivo da didática está em organizar propostas capazes de trazer a ambivalência da tradição: deixar aflorar as vozes dos vencidos, problematizar o monólogo disfarçado de diálogo (Buber, 2009), o pensamento único, o monoculturalismo, sem abrir mão de conhecimentos produzidos socialmente ao longo da história. A didática, como arte de ensinar, não pode prescindir de assumir a tensão entre conservação e ruptura e buscar formas no cotidiano escolar de não silenciar, não discriminar, não oprimir. Esta seria uma resposta de fundo da didática, compromisso da resposta no campo de uma filosofia da educação que não se furta de pensar dialeticamente a educação entre o presente, o passado e o futuro.

\section{Linguagem e Experiência}

No seu texto Experiência e Pobreza Benjamin anuncia que “[...] as ações da experiência (erfahrung) estão em baixa” (Benjamin, 1993, p. 114). Para o autor, a Modernidade traz uma mudança na estrutura da experiência do sujeito. A experiência (erfahrung) inscrita numa temporalidade comum a várias gerações, que pela narrativa cria uma memória coletiva, fruto de um conhecimento que se dá pelo trabalho e, por conseguinte, uma formação; transforma-se em vivência (erlebnis), sensação, impressão forte que precisa ser assimilada às pressas, que produz efeitos imediatos no individuo isolado, privado, incomunicável. Para o autor, a narrativa, que trazia a experiência passada de pessoa para pessoa, foi substitua pela informação que traz a brevidade da novidade carregada de explicações, sem margem às interpretações do sujeito. Uma linguagem empobrecida, sem uma comunidade de ouvintes e sem laços de coletividade. Uma linguagem que se tornou monológica, sem marcas do/no outro.

Para o autor, o homem moderno não aspira às novas experiências, ao contrário, aspira libertar-se de toda experiência, aspira um mundo 
Entre Ciência, Arte e Vida

onde possa ostentar o novo, sem marcas do passado e sem perspectivas de futuro, o imediato e finito, descartável que explicita sua pobreza externa e interna. No seu dia a dia não há tempo para viver a experiência, só há lugar para a vivência que não dá espaço para assimilar o que foi vivido, pois é consequência de um choque permanente, do eternamente novo, sem rastros e sem história.

Benjamin nos anos 1930 critica a cultura do vidro, reflexo da vivência, pondo nua a pobreza da linguagem e da experiência comunicável, a perda da aura da obra de arte, a nova estética (e ética) da recepção das massas e o império da imagem. À época, se referia a uma nova sensibilidade, a uma nova forma de percepção do mundo e do outro. Antecipava um processo que tomou grandes proporções na atualidade. Jameson (1997) aborda algumas características do pós-modernismo - da lógica cultural do capitalismo tardio -, que dão elementos para se pensar a linguagem no mundo contemporâneo que, além da cultura do vidro, abarca elementos que são próprios de uma cultura do plástico, do consumo e do facilmente descartável. São elas: o achatamento; a superficialidade (ou superfícies múltiplas); o esmaecimento do afeto e a frivolidade na cultura pós-moderna; a fragmentação e o isolamento do sujeito; a sincronia no lugar da diacronia; o pastiche da linguagem, trazendo o novo que se repete no sempre igual, a eterna cópia que não distingue o original da reprodução (diferente da paródia que resgata o vivido ressignificando-o); a nova lógica do simulacro; recortes e colagens sobrepondo imagens, canibalizando os estilos e esmaecendo a historicidade; as narrativas descentradas, a estética da fragmentação esquizofrênica, que rompe as cadeias de significação e a temporalidade da sentença, trazendo a primazia do presente, desintegrando o tecido narrativo; e a mudança no espaço construído, o hiperespaço, transformando objetos, relações e sensações. Cada uma destas características apontadas pelo autor merecem desdobramentos, entretanto, este texto limita-se a citá-las para evidenciar os desafios que a educação enfrenta e, consequentemente, as respostas que exige da didática.

Cabe ressaltar que para Benjamin (1993) esta subtração da experiência é uma pobreza que não se limita à esfera privada, mas abraça a todos, inaugurando uma nova barbárie. Mas é o próprio Benjamin que busca uma brecha neste processo e introduz um conceito novo e positivo de barbárie. Novo, pois se aproxima e se afasta da antiga barbárie, uma vez que é fruto do mesmo processo civilizatório iluminista que buscou a sua superação. Positivo, porque esta pobreza de experiência também impele o homem a ir em frente e construir o novo com o pouco que tem. Mais uma vez traz a ambivalência presente em cada mudança, abrindo uma brecha para se pensar numa barbárie positiva.

Kramer (2003, p. 31) anuncia:

[...] trabalhar com linguagem, leitura e escrita, pode ensinar a utopia. Pode favorecer a ação numa perspectiva 
humanizadora, que convida à reflexão, a pensar sobre o sentido da vida individual e coletiva Abrindo-se assim um espaço de luta contra a barbárie.

Konder entende com Benjamin que, “[...] o comportamento lúcido seria procurar a tempo as fissuras por aonde virá a próxima ruptura e pensar a ruína antes que elas se produzam" (Konder, 1999, p. 81). As fissuras da/na linguagem já se evidenciam e é justamente pelas possibilidades de luta contra a barbárie que a linguagem é o ponto chave da didática. A linguagem é constituinte do sujeito, como já posto na introdução. A linguagem inclui o verbal, o não verbal, os gestos, os acentos apreciativos, os presumidos. Inclui o corpo todo, as imagens, as manifestações artísticas no sentido amplo. A linguagem é o eixo do trabalho pedagógico em todas as suas dimensões: desde a forma como o professor se dirige aos estudantes - indagações, vozes que ouve, abertura ao imprevisível - às propostas que faz ao grupo, aos espaços abertos às falas, expressões e manifestações subjetivas, às narrativas que se abrem aos grupo, aos registros individuais e coletivos do que é significativo e que pode constituir a historia individual e coletiva. Linguagem que não se reduz a dimensão instrumental, mas que abarcar os afetos, a sensibilidade, a expressividade.

No agir no mundo produzimos discursos e também somos por eles produzidos. É com a linguagem que nos relacionamos com a cultura a que pertencemos, que vamos produzindo sentidos e significados nas interações que estabelecemos com as pessoas e com as produções culturais que nos cercam, que criamos e recriamos o que está à nossa volta. Nossas falas estão impregnadas de marcas dos nossos grupos sociais de origem, valores e conhecimentos. Nossos modos de falar e de agir fazem parte de nossas bagagens culturais, de vida - são modos de ler a realidade. Assumir uma concepção de linguagem é assumir uma concepção de sujeito. Este princípio é que sustenta o processo de humanização, socialização e subjetivação que objetiva a Educação. Gestos, expressões, olhares, palavras, imagens, silêncios, burburinho, conversas, perguntas, respostas, vozes permeiam o cotidiano escolar. Mas quanto disso tudo se constitui como espaços enunciativos, réplicas, interlocuções?

Para a linguagem se constituir como espaço de luta contra a barbárie, é fundamental que as práticas pedagógicas possibilitem a escuta, as expressões por meio de várias linguagens, a narração de histórias, o registro e memória do grupo, a interlocução com diferentes gêneros discursivos em situações reais e significativas, a abertura de espaços discursivos capazes de favorecer ações e reflexões com a própria linguagem, a leitura e a escrita como experiência e formação, a sensibilização e a apreciação estética de diferentes produções artísticas.

O empobrecimento da linguagem está também nas escolas pelo excesso de controle e até mesmo tutela das produções infantis, pelo uso meramente instrumental das manifestações artísticas, seja a literatura,

Educação \& Realidade, Porto Alegre, v. 40, n. 2, p. 399-419, abr./jun. 2015. 409 
Entre Ciência, Arte e Vida

sejam as outras artes - desenhos, pinturas, modelagens, construções, música, expressão corporal, vídeo. O achatamento e a redução das linguagens pelo lado servil a que se destinam muitas vezes nas escolas evidenciam um desconhecimento da arte e de sua função criadora, uma redução do trabalho com a linguagem - corporal, escrita, visual, musical - ao mero reconhecimento de informações explícitas, pouca problematização e partilha dos sentidos construídos, pouco espaço de troca e de efetiva expressão. Com a linguagem escrita, este processo de instrumentalização, vazio de expressão e de significado partilhado, que muitas vezes acontecem nas escolas, inquietam porque a cisão entre linguagem e vida a destitui do que a constitui: o sentido. E sem sentido crianças e jovens se afastam da possibilidade de apropriação e uso competente da linguagem escrita que é chave para a permanência e progressão na escolaridade e para a inclusão no mundo social letrado.

Buscar formas de pensar o ensino significativo e criativo é um dos maiores desafios da didática. Mais uma resposta responsável na direção de provocar um deslocamento da linguagem de um lugar empobrecido para escovar a história à contrapelo.

A formação de professores, seja inicial ou continuada, não pode prescindir de um trabalho criativo com a linguagem expressiva da literatura e das artes em geral. Nas disciplinas voltadas para as didáticas gerais e especificas a arte faz-se necessário não como apêndice ou ilustração, mas como possibilidade que abre à sensibilidade, à experiência estética, a percepção das diferenças, à alteridade constitutiva. Sem uma formação mais ampliada e sensível no campo da arte corre-se o risco do vazio da continuidade acrítica. Como afirma Geraldi (2010, p. 116) a arte é o lugar do inesperado, como Manuel de Barros desvela em poema que homenageia outro artista, o escritor João Guimarães Rosa:

Passarinho parou de cantar.

Esta é apenas uma informação.

Passarinho desapareceu de cantar.

Este é um verso de J.G. Rosa.

Desapareceu de cantar é uma graça verbal.

Poesia é uma graça verbal (Geraldi, 2010, p. 116).

O trabalho estético com a linguagem só é possível porque seus sentidos e suas formas não são determinados de antemão. Esta percepção nos coloca diante do novo, nos desloca. Uma formação necessária para se deixar afetar pelo outro.

\section{O Desenvolvimento e Aprendizagem: da ação coletiva à ação individual}

Os estudos de Vygotsky trazem importantes contribuições para a educação e para a didática em especial. A questão do desenvolvimento e aprendizagem vale um destaque. Para o autor: 
Toda função psíquica superior surge no processo de desenvolvimento do comportamento duas vezes: inicialmente, como uma função do comportamento coletivo, como forma de colaboração ou interação, como meio de adaptação social, ou seja, como uma categoria interpsicológica, e, pela segunda vez, como meio de comportamento individual da criança, como meio de adaptação pessoal, como um processo interno de comportamento, ou seja, como categoria intrapsíquica (Vygotsky, 1995, p. 307 apud Prestes, 2012, p. 62).

Como se observa, o desenvolvimento se dá de uma ação coletiva, colaborativa para uma ação pessoal. Isto significa dizer que o trabalho colaborativo num grupo amplia as possibilidades de desenvolvimento dos sujeitos. Uma didática implicada com o desenvolvimento dos estudantes precisa, assim, considerar o trabalho coletivo e o lugar do professor na organização do grupo, na disponibilização de recursos e neste processo colaborativo. Nesta via, a busca de formas de agrupamentos diversos numa turma, bem como de propostas variadas de trabalho de grupo não se configuram como meras técnicas ou dinâmicas de grupo para fazer a aula ficar mais interessante, mas como possibilidade de ampliação dos processos de desenvolvimento dos sujeitos, como formas de troca, de interlocução e interação.

Vale ressaltar que há ainda em muitas escolas uma forte presença da disciplinarização e controle de crianças pelos adultos e o predomínio de trabalhos individuais ou de propostas que pressupõem um coletivo silencioso. Ainda que haja mesas coletivas nas salas, pouco se propõe como trabalho de grupo; ainda que a professora organize rodas de conversas, prevalece uma passagem de turno de uma criança para outra de forma burocrática, poucos se escutam, pouco se dialoga. Pesquisas com crianças (Sarmento; Gouvea, 2008; Cruz, 2008; Kramer, 2009; entre outros) têm levado a conclusão de que as práticas pedagógicas têm explorado pouco as possibilidades do grupo, não têm valorizado os processos interativos das crianças e o lugar do grupo na produção de significados e sentidos.

Também abordam a subtração dos espaços coletivos de produção intelectual dos professores nas escolas. Poucos são os momentos de estudo, de reflexão coletiva sobre a prática, de problematização a partir de registros do que foi trabalhado, de troca de experiências, de planejamento cooperativo. As condições de trabalho têm conferido aos professores um lugar pouco criativo e pouco valorizado. Muitos acabam se limitando a repetir o sempre igual, a executar prescrições didáticas de materiais produzidos fora do seu contexto pedagógico. Muitas políticas públicas educacionais têm reiterado esta desqualificação e desautorização dos professores. Há desarticulação entre programas, projetos, secretarias, instituições e professores. Muito do que se faz tem deixado poucas marcas, pela falta de entendimento de que as apropriações se dão das ações coletivas às individuais e não ao contrário. 
Entre Ciência, Arte e Vida

Outra importante colaboração da teoria sócio-histórica para a didática é o conceito de obutchenie termo utilizado por Vygotsky que não tem um equivalente na língua portuguesa. Segundo Prestes:

\begin{abstract}
Obutchenie significa um processo de mão dupla, um processo de instrução ou ensino, mas que não ocorre apenas na direção do professor para o aluno. É uma situação que envolve tanto o aluno quanto o professor e no qual o professor tem o papel de organizador do ambiente social de desenvolvimento. Então, o mais importante, em minha opinião, é a intencionalidade implicada. Não basta a intencionalidade do professor querer ensinar, pois deve-se levar em conta a intencionalidade do aluno querer se envolver com aquilo que está se ensinando. E, de acordo com Vigotski, na atividade de obutchenie o desenvolvimento humano é impulsionado. Então, não é a aprendizagem que antecede o desenvolvimento; o ato intencional de obutchenie, ou seja, a situação de ensino, de estudo ou de instrução impulsiona o desenvolvimento. Mas é preciso lembrar que desenvolvimento, para Vigotski, é uma possibilidade (Prestes, 2012, p. 64).
\end{abstract}

Aqui fica evidente a complexidade do processo de ensino abordada também por Charlot (2006). Não basta o professor querer ensinar, algo precisa ser mobilizado no outro para que ele queira aprender. Cabe ao estudante se envolver com/na situação de ensino que está sendo proposta e ao professor formular propostas mobilizadoras, experimentar diferentes caminhos, ousar, o que implica em se deixar afetar pelo que faz porque o processo de obutchenie, sendo de mão dupla, abarca todos. Esta é uma questão fundamental da didática postulada também por Paulo Freire, ao longo de toda sua obra: no ensinar se aprende e no aprender se ensina. A educação como ato ético, estético, político implica num compromisso com o outro, consigo mesmo, com a sociedade. Não é algo que se faça burocraticamente, que dependa apenas de um elenco de conteúdos ou de receitas prescritivas, mas é algo que se dá na relação com o outro, que inclui muitos saberes e também afeto, compromisso, comprometimento, busca, curiosidade, desejo de conhecer/ aprender, ampliações.

Mais um desafio para a didática como ato responsivo: buscar formas de afetar o outro por via do conhecimento, com vistas à ampliação do olhar, da percepção, do sentir, do imaginar, do conhecer. Tudo isso é movimento, deslocamento de professores e estudantes mobilizados pelo conhecimento. Mas a mobilização exige algo mais do que a organização do que estará em pauta. Na relação triangular entre professores, conhecimentos e alunos, se instaura uma dialogia que inclui um acolhimento mútuo.

Nesta via, tomando a leitura como exemplo, Corsino (2014) evidencia a diferença entre ler para as crianças e ler com as crianças. $\mathrm{O}$ ler com seria uma leitura de corpo inteiro na qual a colocação da voz, 
os acentos expressivos, o ritmo da leitura e do virar das páginas, o brilho nos olhos, a performance do leitor revelam o envolvimento e o gosto pelo que está fazendo. Ler em voz alta se aprende, o gosto pela leitura pode até ser cultivado, mas o espaço de cumplicidade com o grupo, o clima que a relação institui é algo que se conquista por estar por inteiro. Talvez este seja um princípio didático difícil de ensinar aos professores e aos futuros professores. Especialmente no mundo contemporâneo onde tudo nos leva à dispersão e à cisão.

Prestes entende com a teoria de Vygotsky que a preocupação do professor deve ser com o desenvolvimento do outro, ampliando ao máximo o acesso às ferramentas culturais que possibilitam o desenvolvimento:

\begin{abstract}
Vigotski desenvolve o conceito de Zona blijaichego razvitia (Zona de desenvolvimento iminente). A ideia de que o desenvolvimento acontece do plano social, ou coletivo, para o individual é uma das mais importantes e também está contida no conceito de Zona blijaichego razvitia, pois pode ajudar o professor a organizar o ambiente social de desenvolvimento com base na ação colaborativa (Prestes, 2012, p. 62).
\end{abstract}

A questão cultural que perpassa toda teoria vygotskiana em relação à zona de desenvolvimento iminente, ou seja, o que pode ser desenvolvido a partir do coletivo, traz para a didática o compromisso com a ampliação cultural dos estudantes. Assim, cabe à escola disponibilizar diferentes acervos, possibilitar o acesso à informação, às culturas e às artes. $\mathrm{O}$ acesso se dá através de recursos da/na própria escola tais como: uma biblioteca com livros de gêneros diversos, acervos de imagens, filmes, músicas, computadores com internet, espaços para expressão corporal, trabalhos com as artes visuais, a dança e a música, área externa e ao ar livre. Também se dão nos espaços culturais da cidade como museus, centros culturais - concertos e shows musicais, teatro e dança -, centros esportivos e parques, praças e áreas junto à natureza. Uma infraestrutura que diz respeito às políticas e que também inclui o professor e sua formação. É o professor quem organiza o espaço-tempo pedagógico, quem disponibiliza os recursos, quem dá acesso e mobiliza os estudantes. Quando há os recursos, o seu uso depende da forma como são acessíveis. Aqui também a didática é chamada a responder responsivamente aos recursos. O que fazer com que se tem? Sejam diversificados ou limitados, recursos por si mesmos não garantem a qualidade do ensino. Por sua vez, o ensino sem eles, dificilmente, tem qualidade.

A articulação entre ciência, arte e vida, anunciada na introdução, abrange várias possibilidades de inter-relacionar conhecimentos e saberes, de forma dialógica e para além dos muros escolares. O mesmo movimento vale à formação de professores seja na formação inicial ou continuada, seja nas universidades ou no interior da própria escola. 
Entre Ciência, Arte e Vida

Uma educação de qualidade, afirmam Moreira e Candau “[...] deve propiciar ao (à) estudante ir além dos referentes presentes em seu mundo cotidiano, assumindo-o, transformando-se, assim, em um sujeito ativo na mudança de seu contexto" (Moreira; Candau, 2007, p. 21).

\section{A Passagem do Eu Empírico para o Eu Epistêmico}

Charlot salienta que o problema fundamental da educação seria “[...] possibilitar a passagem de um Eu empírico ao Eu epistêmico, ou seja, do individuo preso ao movimento da vida cotidiana ao individuo intelectualmente mobilizado, atento ao saber" (Charlot, 2006, p. 12). Como mobilizar intelectualmente o sujeito de forma a promover tal passagem? Esta é uma questão que traz a estreita relação entre didática e currículo. Forma e conteúdo são indissociáveis e a interface entre educação, cultura e poder aponta o currículo como campo de disputa. As escolhas curriculares não são neutras e não são de simples respostas questões como: Quais os conhecimentos que caberiam à escola ensinar? Quais os que grande parte da população só teria acesso por via da escolarização?

Não é objetivo deste texto aprofundar tais questões, entretanto, não se pode deixar de considerar a função social da escola e do seu lugar na inserção dos estudantes à cultura letrada, no acesso aos conhecimentos científicos, no desenvolvimento intelectual de quem nela ingressa. O conhecimento escolar precisa fazer sentido para quem da escola participa para fazer a diferença em suas vidas. A passagem postulada por Charlot implica na tomada de consciência dos sujeitos do seu próprio processo de apropriação de conhecimentos, da produção de sentido neste processo, da compreensão de tais conhecimentos podem alterar sua relação com o mundo. Mas a passagem se faz nos processos interativos, em colaboração com sujeitos mais experientes capazes de partilhar sentidos e discutir novos conceitos.

Para Vygotsky (2000), o elo central do processo de aprendizagem é a formação de conceitos. O autor compara e inter-relaciona duas categorias de conceitos: os conceitos espontâneos - construídos cotidianamente pela ação direta das crianças sobre a realidade que ela experimenta e observa - e os conceitos científicos - construídos em situações formais de ensino-aprendizagem. Para Vygotsky, os conceitos espontâneos percorrem muitos caminhos até a criança ser capaz de defini-los verbalmente. A apreensão dos sistemas de conhecimento científicos pressupõe um tecido conceitual já amplamente elaborado e desenvolvido por meio da atividade espontânea do pensamento infantil. $\mathrm{O}$ autor destaca, ainda, que o desenvolvimento dos conceitos científicos não é fruto de memorização ou de imitação, pois estes conceitos surgem e se constituem por meio de uma tensão de toda atividade do próprio pensamento infantil: “[...] na medida em que a criança toma conhecimento

414 Educação \& Realidade, Porto Alegre, v. 40, n. 2, p. 399-419, abr./jun. 2015. 
pela primeira vez do significado de uma nova palavra, o processo de desenvolvimento dos conceitos não termina, mas está apenas começando" (Vygotsky, 2000, p. 252).

Estudando as complexas relações entre as duas categorias de conceitos, Vygotsky (2000) observou que embora as crianças consigam operar espontaneamente com uma série de palavras elas não têm consciência da sua definição, ou seja, não conseguem tomar consciência do seu próprio pensamento. Isto é, quanto mais usam automaticamente alguma relação tanto menos têm consciência dela. Por isso, entende que "[...] tomar consciência de alguma operação significa transferi-la do plano da ação para o plano da linguagem, isto é, recriá-la na imaginação para que seja possível exprimi-la em palavras" (Vygotsky, 2000, p. 275). O desenvolvimento consiste, assim, nesta progressiva tomada de consciência dos conceitos e operações do próprio pensamento.

Estas contribuições são bastante provocativas para a didática. Como introduzir os estudantes aos conceitos científicos? Como fazer o deslocamento dos conceitos que estão no plano da ação para o plano do pensamento/linguagem? Quais são as propostas didáticas que podem favorecer as tomadas de consciência dos sujeitos?

Vygotsky considera que a tomada de consciência eleva o pensamento a um nível mais abstrato e generalizado. Sendo assim, pensar sequências didáticas num fluxo que vai da ação à representação e desta à tomada de consciência- com a explicitação verbal do que foi feito- seria um caminho para favorecer a apropriação gradativa de conceitos científicos. Pensar este processo é um exercício intelectual que exige do professor observações, experimentações, reflexões, criatividade e também domínio dos conceitos científicos a serem trabalhados junto aos estudantes. Um desafio à formação de professores e à própria profissão docente, dadas as condições de trabalho já elencadas.

Este processo de apropriação também evidencia a necessidade do professor planejar as propostas, acompanhar os estudantes nas conquistas e dificuldades, avaliar, reorganizar as atividades, mudar estratégias, buscar recursos para alcançar objetivos, organizar o tempo e o espaço onde as ações e interações serão vivenciadas pela turma. A intencionalidade do trabalho pedagógico exige do professor pensar um planejamento contextualizado, cuja historicidade se faz entre o já construído e o porvir. Um pensar na tensão entre a retrospecção e a prospecção, já que processo de apropriação de conhecimento pelos sujeitos embora seja singular, é mobilizado pelo outro, se dá em rede e também em saltos e rupturas.

Para Corsino (2012) algumas características do planejamento são imprescindíveis para que a proposta elaborada pelo professor possa fazer sentido para o grupo, são elas: i) o inacabamento - o planejamento enquanto aberto ao outro implica em trocas, e na acolhida do inusitado; ii) a participação do coletivo - é o coletivo que vai dando acabamento ao 
que foi planejado; iii) a tensão entre previsibilidade e imprevisibilidade; iv) a continuidade e o encadeamento das propostas. O planejamento aberto ao outro exige do professor reflexão, flexibilidade, deslocamento e articulação à avaliação. Esta, por sua vez, só se justifica enquanto possibilidade de professores e alunos reverem percursos, se alterarem. A avaliação desencadeia um novo planejamento. Planejamento e avaliação são instrumentos didáticos fundamentais para o desenvolvimento de uma prática pedagógica reflexiva e comprometida com a mudança, com a participação cultural e social dos estudantes. A resposta responsável da didática se faz também neste conjunto de ações e posições que são tecidas no cotidiano com a intenção de fazer com que algo se mobilize no outro que promova a passagem do Eu empírico para o Eu epistêmico.

\title{
Considerações Finais
}

Pesquisas evidenciam que as dimensões macro e micro da educação se interpenetram e os resultados têm levado a afirmar que a garantia de uma escola democrática, inclui, necessariamente, a ampliação de referências do sujeito, a amplificação cultural, a aprendizagem significativa a partir de um ensino capaz de afetar o sujeito, de aguçar sua curiosidade e o desejo de aprender. Este processo coletivo complexo, que se dá no contexto de uma sala de aula, inserida numa instituição escolar, não se faz de forma improvisada e espontânea. Também não se faz de forma burocrática, padronizada. É um processo que está sujeito a muitas interferências já que a educação é alvo de políticas públicas. Entretanto, como salientam Ball e Mainardes:

\begin{abstract}
Políticas diferentes geram diferentes quantidades de espaços de manobra, mas são sempre objetos de alguma forma de tradução ou de leitura ativa, processos que permitem a compreensão de textos com limites da ação - um processo de re-representação, reordenação, e refundamentação (Ball; Mainardes, 2011, p. 11).
\end{abstract}

Portanto, ainda que projetos sejam determinados por orientações políticas, sua efetivação se dá nas ações e práticas pedagógicas. Numa epistemologia da prática que é situada e que não se dá de forma padronizada ou linear. São sujeito em interação que vão se constituindo mutuamente neste entre ensinar e aprender/abutchenie.

São os atos responsivos do fazer cotidiano, os processos interlocutivos, as interações interpessoais, os sentidos partilhados que dão o tom e o contorno do pode a escola. Assim, a linguagem expressiva pode ser espaço de luta contra a barbárie, a criação, imaginação e o conhecimento como produções coletivas podem provocar ampliações.

O poema Elogio do Aprendizado, de Bertolt Brecht, traz uma provocação e uma convocação para a educação que se quer emancipatória 
e que tem a didática enquanto ato responsivo, que assume o compromisso ético e político de buscar formas de articular ciência, arte e vida no ensinar e aprender do cotidiano escolar.

$$
\begin{aligned}
& \text { Elogio do Aprendizado } \\
& \text { Bertolt Brecht }
\end{aligned}
$$

Aprende o que mais simples! Para aqueles cujo momento chegou, nunca é tarde demais. Aprende o ABC: não basta, mas aprende-o! Não desanimes! Tens de assumir o comando!

Aprende, homem no refúgio! Aprende, homem na prisão! Mulher na cozinha, aprende! Aprende, sexagenário! Tens de assumir o comando! Procura a escola, tu que não tens casa.

Cobre-te de saber, tu que tens frio!

Tu, que tens fome, agarra o livro: é uma arma Tens de assumir o comando!

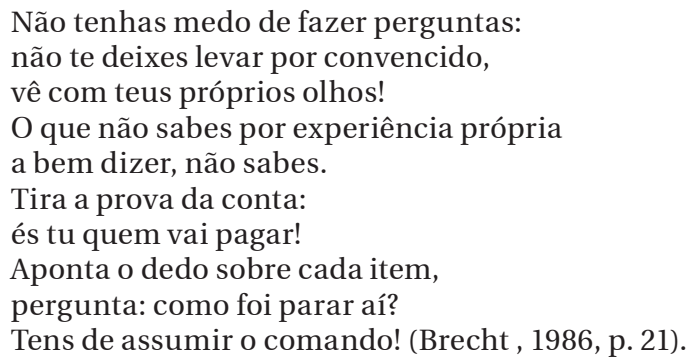

Recebido em 31 de março de 2014 Aprovado em 24 de setembro de 2014

\section{Referências}

ARENDT, Hannah. Entre o Passado e o Futuro. Tradução de Mauro W. Barbosa de Almeida. São Paulo: Perspectiva, 1997.

BAKHTIN, Mikhail. Discurso na Vida e Discurso na Arte. Tradução de Cristóvão Tezza do artigo Discourse in Life and Discourse in Art: concerning sociological poetics. In: VOLOSHINOV, Valentin; BAKHTIN, Mikhail. Freudianism: a marxist critique. New York: Academic Press, 1976.

BAKHTIN, Mikhail. Marxismo e Filosofia da Linguagem. São Paulo: Hucitec, 1992a.

BAKHTIN, Mikhail. Estética da Criação Verbal. São Paulo: Martins Fontes, 1992b.

BAKHTIN, Mikhail. Estética da Criação Verbal. São Paulo: Martins Fontes, 2003. 
BAKHTIN, Mikhail. Para uma Filosofia do Ato Responsável. São Carlos: Pedro e João Editores, 2010.

BALL, Stephen; MAINARDES, Jefferson (Org.). Políticas Educacionais: questões e dilemas. São Paulo: Cortez Editora, 2011.

BENJAMIN, Walter. Obras Escolhidas I: magia e técnica, arte e política. São Paulo: Brasiliense, 1993.

BRECHT, Bertolt. Elogio do Aprendizado. In: BRECHT, Bertolt. Poemas 19131956. São Paulo: Brasiliense, 1986. P. 121

BUBER, Martin. Do Diálogo e do Dialógico. São Paulo: Perspectiva, 2009.

CANDAU, Vera Maria. A Didática em Questão. 10. ed. Petrópolis: Vozes, 1991.

CHARLOT, Bernard. A Pesquisa Educacional entre Conhecimentos, Políticas e Práticas. Revista Brasileira de Educação, Campinas, v. 11, n. 31, p. 7-18, jan./ abr. 2006.

CORSINO, Patrícia. Considerações sobre o Planejamento na Educação Infantil. In: CORSINO, Patrícia (Org.). Educação Infantil: cotidiano e políticas. 2. ed. Campinas: Autores Associados, 2012.

CORSINO, Patrícia (Org.). Travessias da Literatura na Escola. Rio de Janeiro: 7 Letras e FAPERJ, 2014.

CRUZ, Silvia Helena Vieira (Org.). A Criança Fala: a escuta de crianças em pesquisas. São Paulo: Cortez, 2008.

GERALDI, João Wanderley. A Linguagem nos Processos Sociais de Constituição da Subjetividade. In: GERALDI, João Wanderley (Org.). Reflexões sobre Práticas Escolares de Produção de Texto. 1. ed. Belo Horizonte: Autêntica, 2003. P. 15-27. GERALDI, João Wanderley. Ancoragens: estudos bakhtinianos. São Carlos: Pedro e João Editora, 2010.

JAMESON, Fredric. Pós-Modernismo: a lógica cultural do capitalismo tardio. São Paulo: Ática, 1997.

KONDER, Leandro. Walter Benjamin: o marxismo da melancolia. Rio de Janeiro: Civilização Brasileira, 1999.

KRAMER, Sonia. Infância, Cultura Contemporânea e Educação Contra a Barbárie. In: BAZÍLIO, Luis; KRAMER, Sonia. Infância, Educação e Direitos Humanos. São Paulo: Cortez, 2003. P. 83-106.

KRAMER, Sonia (Org.). Retratos de um Desafio: crianças e adultos na Educação Infantil. São Paulo: Ática, 2009.

MOREIRA, Antônio Flávio Barbosa; CANDAU, Vera Maria. Indagações sobre Currículo: currículo, conhecimento e cultura. Brasília: Ministério da Educação; Secretaria de Educação Básica, 2007. Disponível em: <http://www.mec.gov. br>. Acesso em: 23 maio 2014.

PIMENTA, Selma Garrido et al. (Org.). Pedagogia Universitária: caminhos para a formação de professores. São Paulo: Cortez Editora, 2011.

PINO, Angel. As Marcas do Humano: as origens da constituição cultural das crianças na perspectiva de Lev S. Vigotski. São Paulo: Cortez, 2005.

PONZIO, Augusto. A Revolução Bakhtiniana. São Paulo: Contexto, 2008.

PONZIO, Augusto. Introdução: a concepção bakhtiniana de ato. In: BAKTHIN, Mikhail. Para uma Filosofia do Ato Responsável. São Carlos: Pedro e João Editores, 2010. P. 9-39.

418 Educação \& Realidade, Porto Alegre, v. 40, n. 2, p. 399-419, abr./jun. 2015 
PRESTES, Zoia. Lev Vigostski: algumas perguntas, possíveis respostas. In: VAZ, Alexandre Fernandez; MOMM, Caroline Machado (Org.). Educação Infantil e Sociedade: questões contemporâneas. Nova Petrópolis: Editora Nova Harmonia, 2012. P. 57-71.

ROUANET, Sérgio Paulo. Édipo e o Anjo: itinerários freudianos em Walter Benjamin. Rio de Janeiro: Tempo Universitário, 1981.

SARMENTO, Manuel; GOUVEA, Maria Cristina Soares (Org.). Estudos da Infância. Petrópolis: Vozes, 2008.

VYGOTSKY, Lev. A Construção do Pensamento e da Linguagem. Tradução de Paulo Bezerra. São Paulo: Martins Fontes, 2000.

Patrícia Corsino é doutora em Educação pela PUC-Rio, professora da Faculdade de Educação e do Programa de Pós-Graduação em Educação da Universidade Federal do Rio de Janeiro, coordenadora adjunta do Laboratório de Estudos de Linguagem, Leitura, Escrita e Educação- LEDUC e coordenadora do grupo de pesquisa Infância, Linguagem e Escola.

E-mail: corsinopat@gmail.com 